\title{
Parental age is related to the occurrence of cleft lip and palate in Brazilian populations
}

\author{
Paulo Henrique Pimenta de Carvalho ${ }^{1}$, Renato Assis Machado², Silvia Regina de Almeida Reis ${ }^{3}$, \\ Daniella Reis Barbosa Martelli', Verônica Oliveira Dias ${ }^{1}$, Hercílio Martelli-Júnior ${ }^{1,4}$ \\ 'Universidade Estadual de Montes Claros - UNIMONTES, Center of Biological and Health Sciences, Montes Claros, MG, Brazil \\ ${ }^{2}$ Universidade Estadual de Campinas - UNICAMP, Piracicaba Dental School, Department of Oral Diagnosis, Piracicaba, SP, Brazil \\ ${ }^{3}$ Escola Bahiana de Medicina e Saúde Pública - BAHIANA, Department of Basic Science, Salvador, BA, Brazil \\ ${ }^{4}$ Universidade José do Rosário Vellano - UNIFENAS, Center for the Rehabilitation of Craniofacial Anomalies, Alfenas, MG, Brazil
}

\section{Abstract}

Aim: To evaluate the association of environmental risk factors, particularly paternal and maternal age, with gender and type of oral cleft in newborn with nonsyndromic cleft lip with or without cleft palate (NSCL/P). Methods: This study included 1,346 children with NSCL/P of two Brazilian Services for treatment of craniofacial deformities. Parental ages were classified into the following groups: maternal age $<35,36-39$, and $\geq 40$ years; paternal age $<39$ and $\geq 40$ years. The data was analyzed with chi-square test and multinomial logistic regression analysis. The odds ratios were estimated with a 95\% confidence interval. Results: Of the 1,346 children included in this study, CLP was the type of NSCL/P with highest prevalence, followed by, respectively, CL and CP. There was a greater occurrence of NSCL/P in males compared to females (55.8\% versus $44.2 \%)$. CLP was more common in men, while the $C L$ and $C P$ were more prevalent in women $(p=0.000)$. No association between maternal age and clefts was observed $(p=0.747)$. However, there was evidence of association between father's aged $\geq 40$ years old and NSCL/P ( $p=0.031)$. When patients with CP were analyzed separately, no association between the father's age and the child's gender $(p=0.728)$ was observed, i.e. the female gender prevails among patients with $\mathrm{CP}$, regardless of the father's age. Conclusions: This study showed that there were differences in the distribution of the non-syndromic cleft lip and/ or palate and the gender, and fathers aged $\geq 40$ years old may have increased risk of oral cleft. Further studies involving different populations are needed for a better understanding of the effect of maternal and paternal ages as a risk factor for the occurrence of oral clefts.

Keywords: Cleft Palate; Cleft Lip; Paternal Age; Maternal Age; Risk Factors.

\section{Introduction}

Received for publication: November 05, 2016 Accepted: March 07, 2017

Correspondence to: Verônica Oliveira Dias Universidade Estadual de Montes Claros / UNIMONTES - Programa Ciências da Saúde Rua Olegário da Silveira, 125/201

CEP 39400-000 Montes Claros MG, Brazil Phone: +55 38999862934

E-mail: veronicaunimontes@yahoo.com.br
Orofacial malformations are the most common form of congenital anomalies in the world ${ }^{1}$. Nonsyndromic cleft lip with or without cleft palate (NSCL/P) is the most common facial birth defect with lifelong distressing consequences for the patient ${ }^{2}$. The prevalence of NSCL/P varies among different populations. It has an estimated prevalence between 0.36 and 1.54 per 1,000 live births in Brazil ${ }^{3,4}$. The risk factors associated with NSCL/P are not completely understood, but there is a clear interaction between genetic and environmental factors in the etiology of this complex defect ${ }^{5}$. Despite the advances in the identification of risk factors for NSCL/P, there are gaps in the existing knowledge ${ }^{6}$.

As far as embryology is concerned, NSCL/P results from primary defects in the craniofacial fusion, which forms the primary and secondary palates in the first trimester of the intrauterine development ${ }^{7}$. These clinical fissures can be classified, having the 
incisive foramen as an anatomical basis, into four groups: preincisive foramen or cleft lip (CL), post-incisive foramen fissures or cleft palate $(\mathrm{CP})$, trans-incisive foramen fissures or cleft lip and palate (CLP), and rare facial fissures ${ }^{8}$.

CLP is more common in males, while CP is more common in females $^{9,10}$. Males with CLP tend to have a more severe cleft than females and familial CLP is often less severe than sporadic cases ${ }^{9}$. The gender ratio of CLP in the Caucasian population is $1.7: 1$ (male:female) ${ }^{11}$. However, the predominance in males is lower for syndromic forms, which are defined as having other abnormalities present in addition to $\mathrm{CLP}^{12}$. Curiously, the frequency in females is higher when the father's age is greater than 40 years ${ }^{13}$.

To understand the developmental mechanisms underlying NSCL/P, it is essential to review a large and varied field of research ${ }^{14}$. The environmental risk factors for NSCL/P include maternal use of medications such as antiepileptic agents or corticosteroids, smoking and alcohol consumption during pregnancy ${ }^{15}$, intrapartum interval ${ }^{10}$, parity $^{16}$, folic acid deficiencies ${ }^{17}$ and maternal and paternal age ${ }^{5}$. However, there is no consensus on the association of parental age and NSCL/ $\mathrm{P}^{18}$.

Thus, the purpose of this study was to evaluate the association of environmental risk factors, especially paternal and maternal age, with gender and type of cleft of the newborn.

\section{Material and methods}

This study included 1,346 children with NSCL/P, born between the years 2009 and 2013, who visited two Brazilian Services for treatment of craniofacial deformities. The first Service was the Center for Rehabilitation of Craniofacial Anomalies, Dental School, University of Alfenas, Minas Gerais state, which is located in the Southeastern of Brazil. The second Service was the Santo Antonio Hospital, Bahia state, which is located in the Northeastern region of Brazil. All patients were carefully examined and screened for the presence of associated anomalies or syndromes by a team of specialists from each center, and the clefts were classified with the incisive foramen as reference ${ }^{8}$. Paternal ages were classified into the following groups: maternal age $<35,36-39$, and $\geq 40$ years; paternal age $<39$ and $\geq 40$ years $^{18}$. Patients with congenital malformations (other than oral cleft), history of consanguinity or history of familial NSCL/P were not included in this study.

The populations of the two Services have been previously analyzed in respect to ancestry ${ }^{19}$. In the two Services mentioned, the treatment is exclusively done by the Brazilian Public Health System. All information was collected after approval of the Human Research Ethics Committee of both Services. Informed consent was obtained from the parents or guardians of children.

In order to assess the risk factors, an individual instrument (guided questionnaire) was used in both clinics, highlighting the variables of interest to the study. After deploying the questionnaires, the information collected was filed in a data bank and analyzed by the SPSS ${ }^{\circledR}$ version 19.0 statistical software (SPSS Inc., Chicago, USA). The data were analyzed with chisquare test and multinomial logistic regression analysis. The odds ratios (OR) were estimated with a $95 \%$ confidence interval.

\section{Results}

Of the 1,346 children included in this study, CLP had the highest prevalence $(n=750 ; 55.7 \%)$, followed by CL $(n=338$; $25.1 \%)$ and $\mathrm{CP}(\mathrm{n}=258 ; 19.2 \%)$. Table 1 shows the distribution of NSCL/P according to children's gender. There was a greater occurrence of NSCL/P in males compared with females $(55.8 \%$ versus $44.2 \%$ ). CLP was more common in male, while the CL and $\mathrm{CP}$ were more prevalent in females $(\mathrm{p}=0.000)$.

Table 1 - Distribution of non-syndromic cleft lip and/or palate according to type and gender.

\begin{tabular}{lcccccc} 
& \multicolumn{2}{c}{ Cleft palate } & \multicolumn{2}{c}{ Cleft lip } & \multicolumn{2}{c}{ Cleft lip and palate } \\
\cline { 2 - 7 } & $\mathrm{n}$ & $(\%)$ & $\mathrm{n}$ & $(\%)$ & $\mathrm{n}$ & $(\%)$ \\
\hline Gender & & & & & & \\
Male & 93 & 12.4 & 167 & 22.2 & 491 & 65.4 \\
Female & 165 & 27.7 & 171 & 28.8 & 259 & 43.5 \\
& & & & & & \\
Total & 258 & & 338 & & 750 & \\
\hline
\end{tabular}

$\mathrm{p}=0.000$

With respect to distribution of NSCL/P according to type and maternal age (Table 2), a prevalence of mothers under the age of 35 years $(92.4 \%)$ was observed, but no association was found between maternal age and clefts $(p=0.747)$. In this table, information is found from 1,282 mothers, a different number from the total children in the study $(n=1,346)$. This is due to the number of adopted children or subjects without the mother's information.

Table 2 - Distribution of non-syndromic cleft lip and/or palate according to type and maternal age.

\begin{tabular}{lcccccc}
\hline & \multicolumn{2}{c}{ Cleft palate } & \multicolumn{2}{c}{ Cleft lip } & \multicolumn{2}{c}{ Cleft lip and palate } \\
\cline { 2 - 7 } & $\mathrm{n}$ & $(\%)$ & $\mathrm{n}$ & $(\%)$ & $\mathrm{n}$ & $(\%)$ \\
\hline Maternal age & & & & & & \\
(year) & & & & & & \\
$\leq 35$ & 229 & 19.3 & 304 & 25.7 & 652 & 55.0 \\
$\geq 36 \leq 39$ & 14 & 22.2 & 13 & 20.6 & 36 & 57.1 \\
$\geq 40$ & 5 & 14.7 & 11 & 32.4 & 18 & 52.9 \\
Total & 248 & & 328 & & 706 & \\
\hline
\end{tabular}

$\mathrm{p}=0.747$

Table 3 shows the distribution of NSCL/P according to type and father's age. It was observed that most of the men were less than 39 years old $(88.5 \%)$. There was evidence of association between father's aged $\geq 40$ years old and NSCL/P $(p=0.031)$.

Table 4 showed the multinomial logistic regression analysis. It turns out that the chance of occurrence of $\mathrm{CP}$ in relation the CLP was 3.89 times higher $(p=0.00)$ in females compared with males. The chance of CL in relation CLP was 2.15 times higher $(p=0.00)$ in females compared to males. Also, it was noted 
in Table 4 that there is less chance of occurrence of CP when compared with CLP in father's aged $\geq 40$ years old $(p=0.004)$. Patients with CP were analyzed separately. No association between the father's age and the gender was observed $(p=0.728)$. For example, female gender prevailed among patients with $\mathrm{CP}$, regardless of the father's age (data not shown in the table).

Table 3 - Distribution of non-syndromic cleft lip and/or palate according to type and paternal age.

\begin{tabular}{lcccccc} 
& \multicolumn{2}{c}{ Cleft palate } & \multicolumn{2}{c}{ Cleft lip } & \multicolumn{2}{c}{ Cleft lip and palate } \\
\cline { 2 - 7 } & $\mathbf{n}$ & $(\%)$ & $\mathbf{n}$ & $(\%)$ & $\mathbf{n}$ & $(\%)$ \\
\hline $\begin{array}{l}\text { Paternal age } \\
\text { (year) }\end{array}$ & & & & & & \\
$\leq 39$ & 225 & 20.6 & 276 & 25.2 & 593 & 54.2 \\
$\geq 40$ & 16 & 11.3 & 41 & 28.9 & 85 & 59.9 \\
Total & 241 & & 317 & & 678 & \\
\hline$p=0.031$ & & & & & &
\end{tabular}

$p=0.031$

Table 4 - Multinomial logistic regression analysis. Distribution of cleft lip and cleft palate according to gender and paternal age, with reference to the cleft lip and cleft palate.

\begin{tabular}{lcccc}
\hline & Cleft lip & & Cleft palate & \\
\cline { 2 - 5 } & OR (IC95\%) & $p$ value & OR (IC95\%) & $p$ value \\
\hline Gender & 1.00 & & 1.00 & \\
$\begin{array}{l}\text { Male } \\
\text { Female }\end{array}$ & $2.15(1.64-2.82)$ & 0.00 & $3.89(2.85-5.32)$ & 0.00 \\
$\begin{array}{l}\text { Paternal age (year) } \\
\leq 39\end{array}$ & 1.00 & & & \\
$\geq 40$ & $0.95(0.64-1.43)$ & 0.821 & $0.43(0.24-0.76)$ & 0.004 \\
\hline
\end{tabular}

Among female patients with clefts, there was an association between the father's age and the type of cleft $(p=0.003)$. Among the male patients, there was no association between the father's age and the type of cleft $(p=0.092)$ (data not shown in the table).

\section{Discussion}

CLP and CL are most frequent in males, and isolated CP is most typical in females across various ethnic groups. The gender ratio varies with the severity of the cleft and presence of additional malformations, number of affected siblings in the family, ethnic origin, and, possibly, paternal age $\mathrm{e}^{11,13}$. In white populations, the gender ratio for CLP and CL is about 2:1 (male:female) ${ }^{11}$. Moreover, in some studies were observed differences in the distribution of NSCL/P between males and females ${ }^{9,10}$. Investigating the epidemiological features of NSCL/P patients treated at a reference association in Cascavel-Parana, Brazil, Moreira et al. ${ }^{20}$ revealed that CLO, CLP and CPO prevailed in males.

Studies on Brazilian populations showed a predominance of CLP, followed by isolated CL, and $\mathrm{CP}^{9,21}$. In another study done in Brazil involving 126 patients with NSCL/P, we demonstrated a Caucasian predilection and a 1.3 ratio of males to females. Males were 2.57-fold more affected by CLP than females. CLP, with a prevalence of $39.68 \%$, and CL, with a prevalence of $38.09 \%$, were the most common anomalies, followed by CP $(22.23 \%)^{3}$. The findings of the present study reveal that, of the 1,346 patients with $\mathrm{NSCL} / \mathrm{P}$, the prevalence of CLP $(55.7 \%)$ was significantly higher that of CL $(25.1 \%)$ and CP $(19.2 \%)(p=0.000)$. It turns out that there was a greater occurrence of NSCL/P in males compared with females (55.8\% versus $44.2 \%)$ and a 1.26 male-to-female ratio. When isolated CP is evaluated, the proportion of occurrence was 2.23 of female to male. There is also a female predominance with isolated CL (1.29 of female to male). However, when CLP is assessed, the proportion of occurrence was 1.50 male to female.

With respect to maternal age as a risk factor for the occurrence of NSCL/P, we adopted the categories (maternal age <35, 36-39 and $\geq 40$ years) recently cited in a meta-analysis study ${ }^{18}$. In the present study, we found no association between maternal age and clefts $(p=0.747)$. A previous meta-analysis study ${ }^{16}$ showed that the probability of mothers aged between 35 and 39 years having a child with cleft palate was $20 \%$ higher in comparison with those between 20 and 29 years old. For mothers aged 40 years or older, this probability was $28 \%$ higher compared to those aged between 20 and 29 years old. Mothers aged 40 years or older were 1.56 times more likely to have a newborn with cleft lip with or without palate compared to those aged between 20 and 29 years. In a previous study ${ }^{10}$ (2006-2008) with a limited population, it was found that the temporal intervals from 26 to 35 years and older than 35 years had reduced risk of having CLP when compared with women with ages lower than 26 years. In another meta-analysis ${ }^{22}$, no general association between maternal age and CLP was reported. There was a relation between CP and women between 20 and 24 years and older than 30 years old.

It is well known that advanced paternal age ( $>40$ years) is associated with an increased risk of different diseases, such as achondroplasia, Apert syndrome, and neurofibromatosis, and a relation with CLP is possible ${ }^{22}$. In the meta-analysis study ${ }^{18}$, fathers aged 40 years or more showed an increased risk of having a child with CP compared to their peers between 20 and 39 years old. An extensive study suggested predominance in females when the father is age 40 years or older ${ }^{13}$. In a previous study $(2006-2008)^{10}$, paternal age did not show statistically significant association with CLP (OR: 0.7; 95\% CI: 0.36-1.35). In the present study, the occurrence of CP in relation the CLP was 3.89 times higher $(p=0.00)$ in females compared to males, while the chance of CL in relation CLP was 2.15 times higher $(p=0.00)$ in females compared to males (Table 4). It was also observed that there is lower a chance of CP compared with CLP in father's aged $\geq 40$ years old $(\mathrm{p}=0.004)$. When patients with CP were analyzed separately, 
no association between the father's age and the child's gender $(p=0.728)$ was observed. Among female patients with clefts, there was an association between the father's age and the type of cleft $(p=0.003)$. Among male patients, there was no association between the father's age and the type of cleft $(p=0.092)$. The variations of the results presented here need to be confronted with studies in different populations in order to better understand the influence of maternal and paternal age on the risk of occurrence of oral clefts.

In summary, in this study evaluating 1,346 Brazilian children born between the years 2009 and 2013, demonstrated a prevalence of CLP, followed, respectively by CL and CP. In the general distribution, a greater occurrence of clefts was found in males compared with females. CLP was more common in males, while $\mathrm{CL}$ and $\mathrm{CP}$ were more prevalent in females. The maternal age, when analyzed in three different ranges, was not considered as a risk factor for the clefts. When patients with $\mathrm{CP}$ were analyzed separately, no association between the father's age and the gender $(p=0.728)$ was observed. Further studies involving different populations are needed for a better understanding of the effect of maternal and paternal ages as a risk factor on the occurrence of oral clefts.

\section{Acknowledgments}

This work was supported by grants from The Minas Gerais State Research Foundation, Fapemig, Brazil, from the Program Casadinho/Procad (CNPq/Capes), and from the National Council for Scientific and Technological Development-CNPq, Brazil (HMJ).

\section{References}

1. Leslie EJ, Marazita ML. Genetics of cleft lip and cleft palate. Am J Med Genet C Semin Med Genet. 2013 Nov;163C(4):246-58.

2. Rahimov F, Jugessur A, Murray JC. Genetics of nonsyndromic orofacial clefts. Cleft Palate Craniofac J. 2012;49(3):73-91.

3. Martelli-Junior H, Porto LC, Martelli DRB, Bonan PR, Freitas AB, Coletta $\mathrm{RD}$. Prevalence of nonsyndromic oral clefts in a reference hospital in Minas Gerais State, between 2000-2005. Braz Oral Res. 2007;21(4):3147.

4. Rodrigues K, Sena MF, Roncalli AG, Ferreira MA. Prevalence of orofacial clefts and social factors in Brazil. Braz Oral Res. 2009;23(4):38-42.

5. Dixon MJ, Marazita ML, Beaty HT, Murray JC. Cleft lip and palate: understanding genetic and environmental influences. Nature.
2011;12(6):167-78

6. Genisca AE, Frias JL, Broussard CS. Orofacial clefts in the National Birth Defects Prevention Study, 1997-2004. Am J Med Genet A. 2009;149A:1149-58.

7. Meng L, Bian Z, Torensma R, Van der Hoff JW. Biological mechanisms in palatogenesis and cleft palate. J Dent Res. 2009;88(1):22-33.

8. Spina V, Psillakis JM, Lapa FS, Ferreira MC. Classificação das fissuras lábio-palatinas. Rev Hosp Clin Fac Med S Paulo. 1972;27(2):5-6.

9. Martelli DR, Machado RA, Swerts MS, Rodrigues LA, Aquino SN, Martelli Júnior $\mathrm{H}$. Non syndromic cleft lip and palate: relationship between sex and clinical extension. Braz J Otorhinolaryngol. 2012;78(5):116-20.

10. Conway JC, Taub PJ, Kling R, Oberoi K, Doucette J, Jabs EW. Ten-year experience of more than 35,000 orofacial clefts in Africa. BMC Pediatr. 2015;14(15):8.

11. Calzolari E, Pierini A, Astol G, Bianchi F, Neville AJ, Rivieri F. Associated anomalies in multi-malformed infants with cleft lip and palate: An epidemiologic study of nearly 6 million births in 23 EUROCAT registries. Am J Med Genet A. 2007 Mar 15;143A(6):528-37.

12. Mossey P, Castillia E. Global registry and database on craniofacial anomalies. Geneva: World Health Organization, 2003.

13. Berg E, Lie RT, Sivertsen $\AA$, Haaland ØA.Parental age and the risk of isolated cleft lip: a registry-based study. Ann Epidemiol. 2015 Dec;25(12):942-7.e1

14. Setó-Salvia N, Stainer P. Genetics of cleft lip and/or cleft palate: Association with other common anomalies. Eur J Med Genet. 2014;57(8):381-93.

15. Zhang B, Jiao X, Mao L, Xue J. Maternal cigarette smoking and the associated risk of having a child with orofacial clefts in China: a casecontrol study. J Craniomaxillofac Surg. 2011 Jul;39(5):313-8.

16. Luo YL, Cheng YL, Gao XH, Tan SQ, Wang W, Chen Q. Maternal age parity and isolated birth defects: a population-based case-control study in Shenzhen, China. Plos. 2013;8(11):e81369.

17. Bufalino A, Paranaiba LMR, Aquino SN, Martelli Júnior H, Swerts MSO, Coletta RD. Maternal polymorphisms in folic acid metabolic genes are associated with nonsyndromic cleft lip and/or palate in the Brazilian population. Birth Defects Res A Clin Mol Teratol. 2010;88(7):980-6.

18. Herkrath $A P C Q$, Herkrath FJ, Rebelo MAB, Vettore MV. Parental age as a risk factor for non-syndromic oral clefts: a meta-analysis. Journal of Dentistry. 2012;40(6):3-14

19. Aquino SN, Messeti AC, Hoshi R, Borges A, Viena CS, Reis SA et al Analysis of Susceptibility Polymorphisms for Nonsyndromic Cleft Lip with or without Cleft Palate in the Brazilian Population. Birth Defects Res A Clin Mol Teratol. 2014;100(2):36-42.

20. Moreira HSB, Machado RA, de Aquino SN, Rangel ALC, Martelli-Júnior $\mathrm{H}$, Coletta RD. Epidemiological features of patients with nonsyndromic cleft lip and/or palate in Western Parana. Braz J Oral Sci. 2016;15(1):3944.

21. Campos Neves AT, Volpato LE, Espinosa MM, Aranha AM, Borges AH. Environmental factors related to the occurrence of oral clefts in a Brazilian subpopulation. Niger Med J. 2016 May-Jun;57(3):167-72.

22. Vieira AR, Orioli IM, Murray JC. Maternal age and oral clefts: a reappraisal. Oral Surg Oral Med Oral Pathol Oral Radiol Endod. 2002;94(5):530-5. 